TEACHERS OF THE INNER CHAMBERS

Women and Culture in Seventeenth-Century China 



\section{Teachers of the Inner Chambers}

WOMEN AND CULTURE IN SEVENTEENTH-CENTURY CHINA

Dorothy Ko

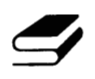

Stanford University Press Stanford, California $\quad 1994$ 
Published with the assistance of China

Publications Subventions and a special grant from the Stanford University Faculty Publication Fund to help support nonfaculty work originating at Stanford.

Stanford University Press

Stanford, California

(C) 1994 by the Board of Trustees of the Leland Stanford Junior University

Printed in the United States of America

CIP data appear at the end of the book

Stanford University Press publications are distributed exclusively by Stanford University Press within the United States, Canada, and Mexico; they are distributed exclusively by Cambridge University Press throughout the rest of the world. 
To my mother and father, Tam Kam-fook and Ko Cheuk-luen, who sent me to the same university as my brother 
